\title{
PPM PELATIHAN SISTEM INFORMASI ADMINISTRASI DAN PENCATATAN KEPENDUDUKAN KAMPUNG GEBANG SIDOARJO
}

\author{
Suzana Dewi ${ }^{*}$, Suryo Atmojo ${ }^{2}$, Krisnadhi Hariyanto ${ }^{3}$ \\ ${ }^{1}$ Teknik Informatika, Universitas Wijaya Putra \\ ${ }^{2}$ Teknik Informatika, Universitas Wijaya Putra \\ ${ }^{3}$ Teknik Industri, Universitas Wijaya Putra
}

emailsuzanadewi@uwp.ac.id, suryoatmojo@uwp.ac.id, krisnadi@uwp.ac.id

\begin{abstract}
Abstrak
Penyampaian informasi di lingkungan RW VIII Kelurahan Gebang ternyata masih dilakukan secara tradisional melalui surat edaran maupun pemberitahuan secara langsung. Hal ini terlihat kurang efisien, karena hanya disampaikan secara lisan. Informasi penting yang seharusnya diterima oleh masyarakat, khususnya di lingkungan Kelurahan Gebang, akhirnya menjadi kurang dimengerti, kurang merata dan lambat. Pada mutu layanan, didapati rendahnya partisipasi masyarakat dalam mendukung terciptanya Sistem Informasi yang benar. Dan pada kondisi riil Mitra terdapat masalah yaitu belum sepenuhnya memenuhi standar Sistem Informasi Manajemen di Tingkat RW. Untuk itu diperlukan adanya penerapan sebuah aplikasi atau Sistem Informasi terpadu yang dapat membantu mitra dalam pengakuratan data peristiwa penduduk. Pemuktahiran data dapat dilihat menggunakan media informasi secara online. Aplikasi tersebut adalah Sistem Data Kependudukan (SIDAK). Setelah menggunakan Aplikasi Sistem Data Kependudukan (SIDAK) maka proses pendataan penduduk di RW VIII kelurahan Gebang, baik bagi warga yang datang, maupun warga yang pindah ke tempat lain menjadi lebih mudah dan resiko kesalahan pencatatan penduduk menurun. Karena dengan menggunakan aplikasi tersebut, petugas di lingkungan RW VIII Kelurahan Gebang dapat memantau langsung perkembangan penduduk setiap saat.
\end{abstract}

Kata Kunci : Sistem kependudukan, efisien, komputerisasi

\begin{abstract}
Submission of information in the RW VIII Gebang Village is still done traditionally through circulars or direct notifications. This seems less efficient, because it is only conveyed orally. Important information that should be received by the community, especially in the Gebang Village environment, eventually becomes poorly understood, uneven and slow. In terms of service quality, it was found that there was a low level of community participation in supporting the creation of a correct Information System. And in the real condition of Partners, there is a problem that is not yet fully meeting the standards of the Management Information System at the RW Level. For this reason, it is necessary to implement an application or an integrated information system that can assist partners in the accuracy of population event data. Updating data can be viewed using online information media. The application is the Population Data System (SIDAK). After using the Population Data System Application (SIDAK), the population data collection process in RW VIII, Gebang sub-district, both for residents
\end{abstract}


who come, and residents who move to other places becomes easier and the risk of population registration errors decreases. Because by using this application, officers in the RW VIII Gebang Village can directly monitor the development of the population at any time.

Keywords: population system, efficient, computerized

\section{PENDAHULUAN}

\section{A. Analisis Situasi}

Komputer merupakan salah satu kemajuan teknologi yang dalam perkembangannya, bisa sangat membantu tugas pelayanan instansi pemerintah untuk meningkatkan pelayanan di masyarakat.

Teknologi informasi memberi andil yang besar terhadap perubahan mendasar dalam berbagai sektor kehidupan. Seperti dalam kegiatan pada sektor struktur operasi, manajemen organisasi, pendidikan, transportasi dan kesehatan serta penelitian. (Rusydi, Juli 2017) Informasi kependudukan merupakan salah satu faktor utama dalam pemerintahan di tingkat terbawah (RT/ RW), karena dengan informasi kependudukan ini maka dapat memudahkan dan mempercepat untuk memperoleh informasi yang terdapat di wilayah tingkat RW dan Kelurahan.

Penyampaian informasi berupa surat edaran maupun pemberitahuan secara langsung dan lisan kerap terjadi di lingkungan RW VIII Kelurahan Gebang, Ini mengakibatkan berbagai informasi yang seharusnya diterima oleh masyarakat khususnya di lingkungan Kampung Gebang menjadi kurang efisien.
Menurut Chindra Saputra dan Effiyaldi: penting untuk menganalisis dan merancang data kependudukan,dengan database yang terpusat. Untuk itu digunakan Metode UML ( Unified Modeling Language ) untuk merancang sistem administrasi kependudukan. Sehingga menghasilkan perancangan sistem informasi administrasi dengan pengolahan data kependudukan yang terintegrasi. Adapun sistem informasi terserbut terintegrasi dengan pembuatan surat-surat keterangan dan juga pelaporan kegiatan penduduk. Setelah itu rancangan akan dapat diimplementasikan dan dapat menjadi referensi pembelajaran. (Chindra, 2017)

Menurut Fikry : kesalahan dan kehilangan data kerap terjadi dalam pengolahan data kependudukan . Untuk itu, diperlukan database Pemetaan Kependudukan berbasis komputerisasi untuk mempermudah dalam pengolahan data serta menghasilkan laporan yang diinginkan. Untuk menganalisa pembuatan database kependudukan penting memperhatikan aspek-aspek seperti kriteria aspek kebenaran (correctness), aspek kelengkapan (completeness), aspek minimalitas (minimality)dan aspek konsistensi (consistency) serta aspek relevansi (relevance). Sehingga dengan demikian perancangan database yang dihasilkan dapat dilakukan dengan optimal. (Fikry, 2016)

Teknologi Informasi dan Komunikasi 12 
Teknologi informasi berbasis web menghasilkan keakuratan baik dari segi waktu maupun biaya. Dan informasi yang dihasilkan dapat diakses kapan saja dan dimana saja. Dengan memanfaatkan aplikasi berbasis web diharapkan dapat memberikan informasi yang akurat dan cepat, yang nantinya dapat membantu masyarakat dalam memperoleh informasi lebih up to date. (Erlinda, Juni 2018 )

Pengembangan rekayasa dan pemodelan sistem, analisis kebutuhan, desain, pengkodean, pengujian dan pemeliharaan adalah metode yang digunakan dalam aplikasi pencatatan kependudukan. Salah satu kelebihannya adalah dapat menampilkan untuk setiap bulan jumlah penduduk. (Ali Ibrahim, April 2016)

Berdasarkan masalah di atas, terdapat beberapa permasalahan yang inti masalahnya adalah belum adanya sistem database sosial-spasial di Gebang. Oleh karena itu, maka tim pelaksana mencoba memberikan solusi guna mengatasi permasalahan yang ada tersebut, diantaranya adalah penerapan sebuah aplikasi atau sistem yang dapat membantu dalam pengakuratan data peristiwa penduduk. Aplikasi tersebut berupa sebuah Sistem Data Kependudukan (SIDAK).

\section{Profil Mitra}

Komplek Perumahan Citra Fajar Golf di RW VIII berada di Kelurahan Gebang, Kecamatan Sidoarjo, Kabupaten Sidoarjo, Provinsi Jawa Timur. Komplek ini merupakan komplek perumahan yang perbedaan elevasinya pada luasan rumah satu Kartu
Keluarga (KK) sebesar $\pm 72 \mathrm{~m} 2$. Adapun luasan kelurahan Gebang mencapai $1.527 \mathrm{Ha}$ dengan batas-batas wilayah sebagai berikut :

- batas utara : Desa Rangka Kidul,

- batas timur : Desa Kupang,

- batas Selatan : Desa Wedoro Klurak, dan

- batas selatan : Kelurahan Sekardangan.

Secara umum mata pencaharian penduduk penduduk Kelurahan Gebang ini beranekaragam, namun didominasi oleh karyawan swasta.

Berikut ini adalah gambaran umum Kelurahan Gebang Sidoarjo.

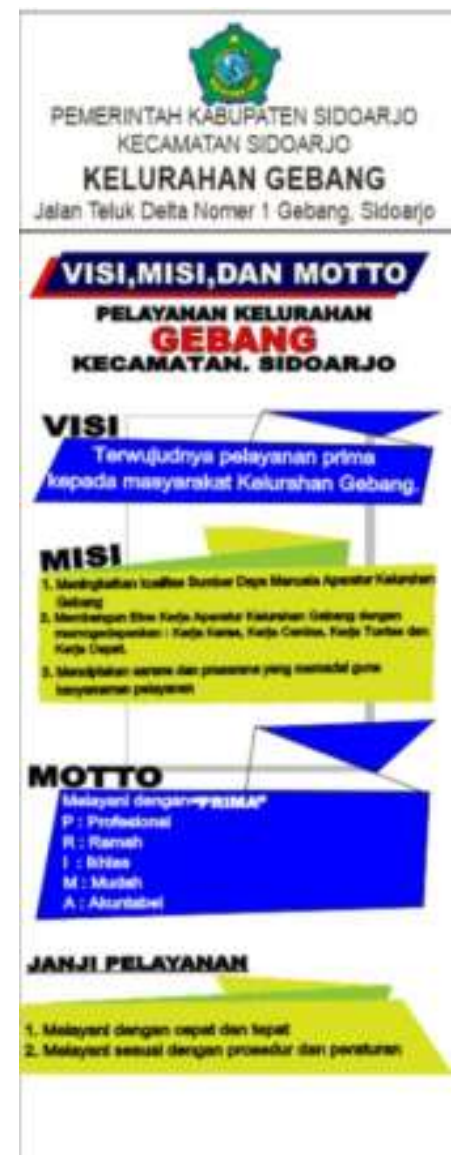

Gambar 1. Visi, Misi dan Moto Kelurahan Gebang

Teknologi Informasi dan Komunikasi 13 
a) Visi

Terwujudnya pelayanan prima kepada masyarakat kelurahan Gebang.

b) Misi

- Meningkatkan kualitas Sumber Daya Manusia Aparatur Kelurahan Gebang.

- Membangun Etos Kerja Aparatur Kelurahan Gebang dengan mengedepankan : Kerja Keras, Kerja Cerdas, Kerja Tuntas, dan Kerja cepat.

- Menciptakan Sarana dan Prasarana yang memadai guna kenyamanan pelayanan.

c) Motto

Melayani dengan Profesional, Ramah,

Ikhlas, Mudah, Akuntabel

d) Janji Pelayanan

- Melayani dengan cepat dan tepat

- Melayani sesuai prosedur dan peraturan.

e) Komposisi Penduduk

Berikut ini data yang diperoleh dari

Kelurahan Gebang.

Tabel 1 Komposisi Penduduk RW Gebang Sidoarjo Berdasarkan Jenis Kelamin

\begin{tabular}{|l|l|c|}
\hline No. & Jenis Kelamin & Keterangan \\
\hline 1. & Laki-laki & 1.295 \\
\hline 2. & Perempuan & 1.265 \\
\hline \multicolumn{2}{|c|}{ Jumlah } & 2.560 \\
\hline
\end{tabular}

Tabel 2 Komposisi Penduduk RW Gebang Sidoarjo Berdasarkan Agama

\begin{tabular}{|r|l|c|}
\hline No. & Agama & $\begin{array}{l}\text { Jumlah } \\
(\%)\end{array}$ \\
\hline 1. & Islam & 87.18 \\
\hline 2. & Kristen & 6.96 \\
\hline 3. & Katolik & 2.91 \\
\hline 4. & Hindu & 1.69 \\
\hline 5. & Budha & 0.72 \\
\hline 6. & Agama lain & 0.54 \\
\hline \multicolumn{2}{|c|}{ Jumlah } & 100 \\
\hline
\end{tabular}

Tabel 3 Komposisi Penduduk RW Gebang Sidoarjo Berdasarkan pekerjaan

\begin{tabular}{|c|l|c|}
\hline No. & Pekerjaan & $\begin{array}{l}\text { Jumlah } \\
\text { Orang (\%) }\end{array}$ \\
\hline 1. & Karyawan swasta & 16.80 \\
\hline 2. & Belum / tidak bekerja & 2.52 \\
\hline 3. & Pelajar / mahasiswa & 21.30 \\
\hline 4. & PNS & 0.32 \\
\hline 5. & TNI/ Polri & 0.10 \\
\hline 6. & Perdagangan & 7.34 \\
\hline 7. & Petani / pekebun & 1.14 \\
\hline 8. & Nelayan/ Ikan & 0.18 \\
\hline 9. & Industri & 11.35 \\
\hline 10. & Transportasi & 0.14 \\
\hline 11. & Karyawan Swasta & 1.26 \\
\hline 12. & Karyawan BUMN & 0.04 \\
\hline 13. & Karyawan Honorer & 0.08 \\
\hline 14. & Buruh HarianLepas & 11.23 \\
\hline 15. & Buruh Tani / Kebun & 9.01 \\
\hline 16. & Dokter/ Medis & 0.18 \\
\hline 17. & Wiraswasta & 15.77 \\
\hline 18. & Lainnya & 1.25 \\
\hline Jumlah & 100 \\
\hline
\end{tabular}

Sumber data : Kelurahan Gebang

\section{Permasalahan Mitra}

Permasalahan mitra yang mendasar pada sistem belum menunjukan adanya sistem informasi terpadu ditingkat RW. Sehingga perangkat Kampung Gebang tidak dapat terintegrasi kepada masyarakat. Hal ini menyebabkan kekacauan data kependudukan.

Teknologi Informasi dan Komunikasi 14 
Berdasarkan permasalahan tersebut dapat digambarkan sebagai berikut :

1. Partisipasi Masyarakat kurang memadai dalam mendukung Terciptanya Sistem Informasi yang benar. Selama ini warga Kampung Gebang menyerahkan sepenuhnya kepada perangkat Kampung Gebang RW VIII. Namun di sisi lain, pendataan kependudukan ini sangat diharapkan oleh beberapa lapisan masyarakat tertentu. Mereka berharap Perangkat Kampung Gebang Sidoarjo dapat melihat kondisi warga sebenarnya sehingga menggerakkan partisipasi warga Kampung Gebang Sidoarjo untuk mendukung adanya sistem informasi yang benar.

2. Sistem Manajemen Kependudukan di Tingkat Rukun Warga (RW) Kampung Gebang Sidoarjo belum tertata dengan baik. RW Gebang telah memiliki data warga setempat dalam bentuk dokumen manual dan penyerahan data yang diserahkan pada setiap RT. Kategori informasi yang didapat berdasarkan data penduduk dapat dilihat secara manual dari data perangkat Kampung Gebang. Pengecekan data warga dapat didasarkan pada berkas kependudukan yang diterima perangkat Kampung Gebang.

Berikut ini adalah gambaran proses administrasi dan pencatatan yang dilakukan oleh perangkat Kampung Gebang RW VIII. Dimana proses yang dilakukan masih secara manual. Warga yang berkepentingan harus datang memberikan berkas berupa Kartu Keluarga dan Kartu Tanda Penduduk (KTP) sebagai persyaratan utama untuk pencatatan kependudukan baik saat kedatangan maupun kepindahan penduduk Kampung Gebang Sidoarjo.

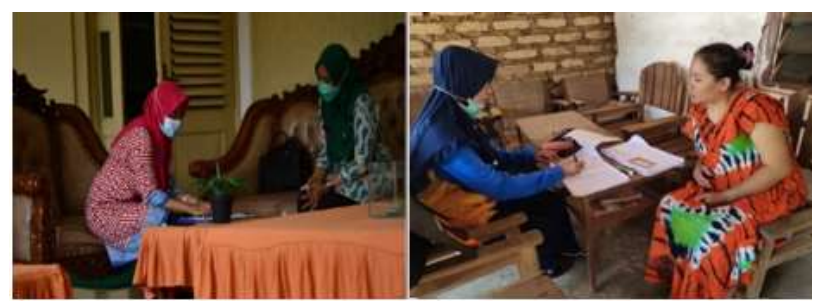

Gambar 2. Pencatatan Kartu Keluarga dan KTP.

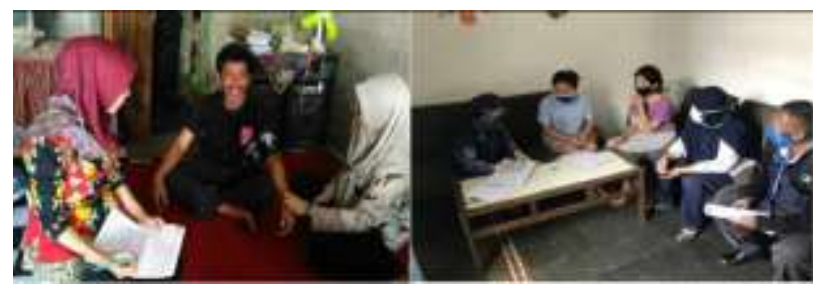

Gambar 3. Pencatatan Kedatangan dan

Kepindahan PendudukUntuk permasalahan mitra dapat dilihat dalam tabel 4 berikut ini .

\begin{tabular}{|c|c|c|c|}
\hline No. & $\begin{array}{l}\text { Aspek } \\
\text { Permasalahan }\end{array}$ & $\begin{array}{l}\text { Permasa- } \\
\text { lahan }\end{array}$ & Solusi \\
\hline 1 & Mutu Layanan & $\begin{array}{l}\text { Rendahnya } \\
\text { Partisipasi } \\
\text { Masyaraka } \\
\text { t dalam } \\
\text { Mendukun } \\
\text { g } \\
\text { Terciptany } \\
\text { a Sistem } \\
\text { Database } \\
\text { Sosial- } \\
\text { Spasial } \\
\text { yang } \\
\text { Valid. }\end{array}$ & $\begin{array}{l}\text { Menciptakan } \\
\text { kemudahan, } \\
\text { keakuratan } \\
\text { dan } \\
\text { kecepatan } \\
\text { dalam } \\
\text { pendataan } \\
\text { penduduk } \\
\text { beserta } \\
\text { laporannya. }\end{array}$ \\
\hline 2 & Manajemen & $\begin{array}{l}\text { Belum } \\
\text { Tertatanya } \\
\text { Sistem } \\
\text { Manajeme } \\
\text { n } \\
\text { Database } \\
\text { Sosial- }\end{array}$ & $\begin{array}{l}\text { Penerapan } \\
\text { sebuah } \\
\text { aplikasi atau } \\
\text { system yang } \\
\text { dapat } \\
\text { membantu } \\
\text { mitra dalam }\end{array}$ \\
\hline
\end{tabular}

Teknologi Informasi dan Komunikasi 15 
Tabel 4 Aspek Permasalahan dan Solusi:

\begin{tabular}{|l|l|l|} 
Spasial di & $\begin{array}{l}\text { pengakuratan } \\
\text { dingkat } \\
\text { RW. } \\
\text { peristiwa } \\
\text { penduduk. }\end{array}$ \\
\hline
\end{tabular}

\section{Solusi dan Target Luaran}

Penerapan sebuah aplikasi atau sistem yang dapat membantu mitra dalam pengakuratan data diharapakan dapat menjadi solusi terhadap permasalahan yang terjadi pada mitra. Salah satu alternatif solusinya ada menggunakan sebuah aplikasi berupa Sistem Data Kependudukan (SIDAK).

Tabel 5 Solusi Dan Target PPM Pelatihan Sistem Informasi Administrasi dan Pencatatan Kependudukan Gebang Sidoarjo

\begin{tabular}{|l|l|l|l|}
\hline N & $\begin{array}{l}\text { Permasa- } \\
\text { lahan Mitra }\end{array}$ & Solusi & Target \\
\hline 1 & $\begin{array}{l}\text { Rendahnya } \\
\text { sumber daya } \\
\text { teknologi } \\
\text { pengelolaan } \\
\text { data } \\
\text { administrasi } \\
\text { khususnya } \\
\text { kependuduk } \\
\text { an. }\end{array}$ & $\begin{array}{l}\text { Membuat } \\
\text { aplikasi } \\
\text { Sistem } \\
\text { Informasi } \\
\text { Kependuduk }\end{array}$ & $\begin{array}{l}\text { Perangkat } \\
\text { dapat mudah } \\
\text { mengakses } \\
\text { data } \\
\text { kependuduka } \\
\text { n yang } \\
\text { dibutuhkan. }\end{array}$ \\
\hline 2 & $\begin{array}{l}\text { Rendahnya } \\
\text { pengetahuan } \\
\text { teknologi } \\
\text { terkait } \\
\text { SIDAK. }\end{array}$ & $\begin{array}{l}\text { Pelatihan } \\
\text { dan } \\
\text { penggunaan } \\
\text { SIDAK. }\end{array}$ & $\begin{array}{l}\text { Memaksimal } \\
\text { kan } \\
\text { penguasaan } \\
\text { terhadap } \\
\text { sistem } \\
\text { informasi } \\
\text { SIDAK. }\end{array}$ \\
\hline
\end{tabular}

Langkah-langkah yang tim pelaksana adalah sebagai berikut :

a. Mempersiapkan perangkat Kampung Gebang untuk mengumpulkan data penduduk dengan mengumpulkan Kartu Keluarga (KK).

b. Memberikan pelatihan, pembinaan dan pendampingan kepada semua perangkat Kampung Gebang Sidoarjo mengenai Sistem Data Peristiwa Penduduk (SIDAK)

c. Memberikan pendampingan Perangkat Kampung Gebang yang ditunjuk untuk memegang aplikasi Sistem Data Kependudukan.

Adapun target yang ingin dicapai dalam kegiatan PPM ini adalah :

a. Pemberdayaan dan peningkatan sumber daya manusia khususnya masyarakat Kampung Gebang Sidoarjo melalui Sistem Informasi Kependudukan di lingkungan RW Gebang Sidoarjo yang berbasis Iptek yang berkelanjutan.

b. Mensinergikan kebijakan pemerintah daerah dan kepakaran perguruan tinggi serta kearifan lokal dari masyarakat Kampung Gebang Sidoarjo sehingga dapat mengangkat potensi yang dimilikinya.

\section{B. Metode}

Kegiatan PPM yang akan dilakukan bagi masyarakat di RW Gebang Sidoarjo dibagi menjadi beberapa bagian, dengan penjadwalan sebagai berikut :

Teknologi Informasi dan Komunikasi 16 
1. Koordinasi jadwal dan tempat pelaksanaan pelatihan dengan mitra.

2. Kegiatan untuk mempersiapkan segala sesuatu untuk pelaksanaan pelatihan dan sosialisasi masyarakat Kampung Gebang Sidoarjo.

3. Penyuluhan pertama tentang pentingnya masyarakat Kampung Gebang Sidoarjo untuk memberikan data berupa KTP dan Kartu Keluarga untuk pemutakhiran data peristiwa penduduk terhadap RT dan RW Gebang Sidoarjo.

4. Penyuluhan kedua untuk memberikan pelatihan dan pembinaan mengenai Sistem Data Kependudukan kepada perangkat Kampung Gebang Sidoarjo yang telah di tunjuk oleh Ketua Rukun Warga(RW) Kampung Gebang Sidoarjo.

5. Pelatihan administrasi dan pencatatan kependudukan.

6. Memberikan pendampingan mengenai Sistem Data Kependudukan kepada Perangkat Kampung Gebang Sidoarjo (SIDAK) yang telah ditunjuk bagaimana cara menggunakan aplikasi yang digunakan untuk pengisian data penduduk berdasarkan Kartu Tanda Penduduk (KTP) dan Kartu Keluarga(KK).

7. Pelatihan untuk mengolah, menggunakan dan membaca rekapitulasi laporan kependudukan yang telah dihasilkan oleh
Sistem Informasi Kependudukan kepada Perangkat Kampung Gebang Sidoarjo.

8. Evaluasi Proses PPM Pelatihan Sistem Informasi Administrasi dan Pencatatan Kependudukan Kampung Gebang Sidoarjo Kuisioner yang telah dibagikan akan dianalisa untuk mengetahui apakah pelatihan Sistem Informasi Administrasi dan Pencatatan Kependudukan yang dilakukan sudah sesuai dengan tujuan kegiatan pelatihan ini. Evaluasi ini juga bertujuan untuk sebagai bahan masukan pelatihan-pelatihan selanjutnya pada program pengabdian kepada masyarakat dikesempatan berikutnya. Selain itu agar dapat memberi tambahan informasi yang belum tercapai selama pelaksanaan pelatihan yang telah berlangsung di Kampung Gebang Sidoarjo.

\section{Hasil dan Pembahasan}

Hasil yang diperoleh dari PPM bagi masyarakat dapat adalah sebagai berikut :

1. Perangkat Kampung Gebang dapat mudah mengakses data kependudukan yang dibutuhkan.

2. Perangkat Kampung Gebang mampu memaksimalkan penguasaan terhadap sistem informasi SIDAK.

\section{Evaluasi Pelaksanaan Program dan Keberlanjutan Program PPM}

Evaluasi kegiatan PPM bagi Masyarakat ini diharapakan dapat memberikan hal yang baik pandangan positif khususnya dari Perangkat

Teknologi Informasi dan Komunikasi 17 
Kampung Gebang Sidoarjo. Kegiatan PPM ini diimplementasikan dalam bentuk sosialisasi kegiatan Sistem Informasi Kependudukan. Kegiatan sosialisasi ini terdiri dari penyuluhan, pelatihan, pembinaan dan pendampingan terhadap Perangkat Kampung Gebang Sidoarjo. Dengan dilakukan kegiatan ini diharapkan dapat membantu dalam pencatatan data peristiwa penduduk. Sosialisasi Sistem Informasi Kependudukan dilaksanakan untuk memberikan informasi dan pengetahuan tentang pencatatan atau penghitungan jumlah data penduduk kepada Perangkat Kampung Gebang Sidoarjo. Berbagai pihak terlibat dalam pelaksanaan pengawasan kegiatan PPM bagi Masyarakat. Sehingga untuk setiap kegiatan yang dilaksanakan dibawah pengawasan yang baik. Adapun pengawasan terhadap kegiatan PPM bagi Masyarakat yang terealisasi dengan sosialisasi Sistem Informasi Kependudukan yang dilakukan oleh Ketua RW dan LPPM Universitas Wijaya Putra Surabaya.

\section{Program Dilapangan Setelah Kegiatan PPM} Selesai Dilaksanakan

Evaluasi selalu diperlukan dalam setiap pelaksaan program PPM. Pada proses ini dibahas setiap permasalahan yang ada atau permasalahan yang timbul akibat adanya kegiatan PPM bagi Masyarakat di RT/RW Kampung Gebang Sidoarjo. Dimana proses evaluasi dilakukan setiap akhir pekan dengan cara dilakukannya rapat kecil dengan perwakilan Perangkat Kampung Gebang Sidoarjo untuk membicarakan kegiatan yang telah berlangsung.

Namun ada banyak hal lain lagi yang sangat diperlukan dalam berhasilnya kegiatan pelatihan ini. Hal ini bermanfaat untuk melengkapi sekaligus memperbaiki aplikasi atau Sistem Informasi Administrasi dan Pencatatan Kependudukan yang dilaksanakan di Kampung Gebang Sidoarjo, yaitu :

a. Pentingnya secara terus menerus melakukan pencatatan data peristiwa penduduk agar Perangkat Kampung Sidoarjo mendapatkan data penduduk Kampung Gebang Sidoarjo yang sebenar-benarnya.

b. Perlunya penambahan pada kemampuan Sistem Informasi Administrasi dan Kependudukan Kampung Gebang Sidoarjo agar dapat mengetahui kepemilikan dari Kartu Tanda Penduduk (KTP).

c. Perlunya penambahan pada kemampuan Sistem Informasi Administrasi dan Kependudukan Kampung Gebang Sidoarjo agar dapat mengetahui kepemilikan dari Kartu Keluarga (KK).

d. Perlunya penambahan kemampuan Sistem dalam SIDAK akan ditambah kemampuannya untuk dapat mengetahui data migrasi penduduk Kampung Gebang Sidoarjo yang terbaru.

e. Perlunya penambahan kemampuan Sistem untuk dapat mengetahui kedatangan dan kepindahan penduduk yang terjadi dalam Kampung Gebang Sidoarjo.

Teknologi Informasi dan Komunikasi 18 
Gambar 4 Alur Proses Data SIDAK

\section{Proses Alur Data}

Dalam proses administrasi dan pencatatan kependudukan , berikut ini adalah langkah-langkah yang harus dilakukan oleh perangkat Kampung Gebang Sidoarjo adalah sebagai berikut :

1. Pemrosesan data masuk RT.

Warga menyerahkan berkas berupa KTP dan KK kepada Ketua RT masingmasing.Ketua RT akan meneruskan berkas kependudukan kepada Ketua RW.

2. Pemrosesan data keluar RT.

Ketua RT menyerahkan data keluar penduduk berupa KTP dan KK kepada Ketua RW.

3. Pemrosesan laporan.

Setiap Ketua RT akan melaporkan kepada Ketua RW apabila ada warga baru yang baru pindah ke Kampung Gebang Sidoarjo. Ketua RW akan memberikan laporan kepada setiap Ketua RT apabila ada warga yang keluar setiap 1 bulan sekali.

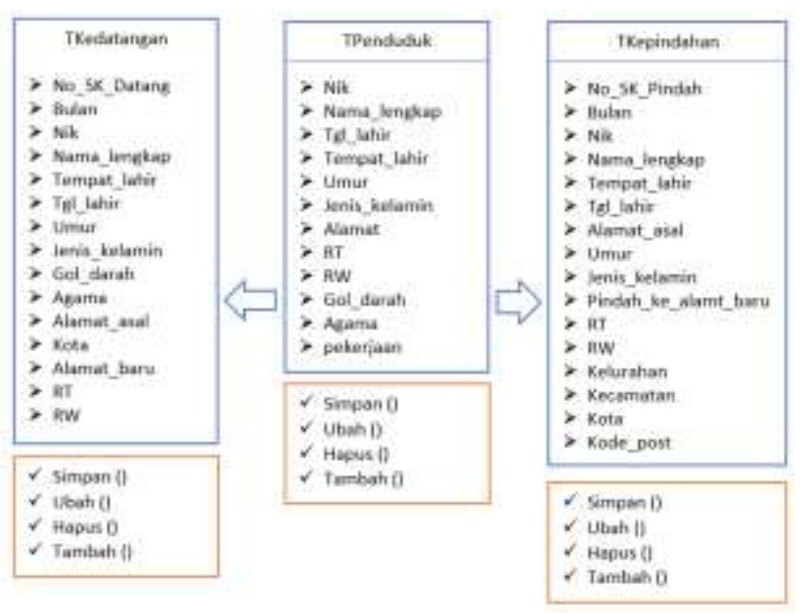

Gambar diatas menunjukan bagaimana alur data yang akan digunakan pada aplikasi Sistem Informasi Administrasi dan Pencatatan Kependudukan Kampung Gebang Sidoarjo.

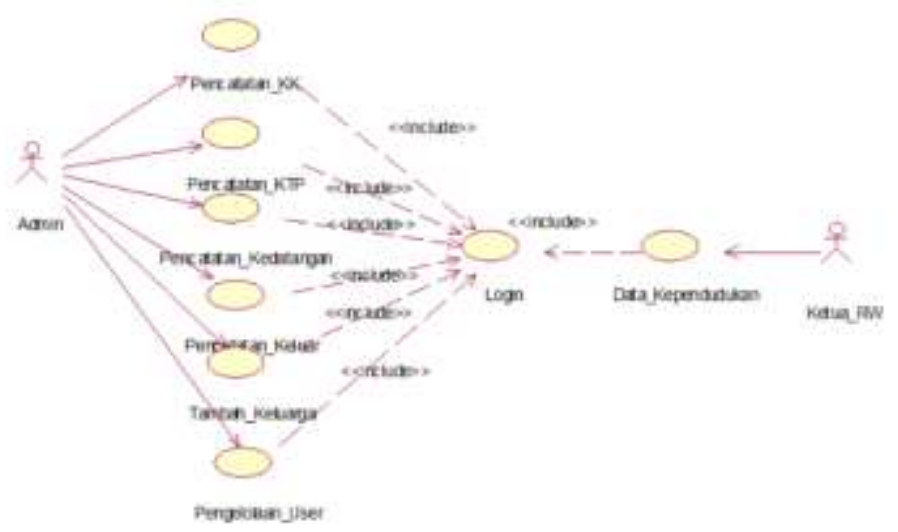

Gambar 5 Rancangan Sistem Informasi Administrasi dan Pencatatan Kependudukan Kampung Gebang

Dari kegiatan pertemuan yang intensif dengan perangkat Kampung Sidoarjo, gambar 5 menunjukkan hasil rancangan Sistem Informasi menggunakan Unified Modeling Language (UML). Pemodelan ini menggambarkan hasil analisis kebutuhan dari Kampung Gebang Sidoarjo. Dimana Sistem Informasi Administrasi dan Pencatatan Kependudukan ini dilakukan oleh admin yang telah di tunjuk oleh Perangkat Kampung Gebang. Sistem Informasi menyediakan wadah untuk melakukan pencatatan KTP, pencatatan KK, pencatatan kedatangan dan pencatatan keluar penduduk. Kemudian hasil dari sistem informasi yang berupa data kependudukan terkini dapat di awasi oleh

Teknologi Informasi dan Komunikasi 19 
Ketua Rukun Warga (RW) atau Perangkat Kampung Gebang Sidoarjo yang telah ditunjuk.

\section{Daftar Pelatihan}

Berikut ini adalah daftar analisis kebutuhan PPM Pelatihan Sistem Informasi Administrasi dan Pencatatan Kependudukan Kampung Gebang Sidoarjo (dapat dilihat di Tabel 6).

Tabel 6 Analisis Kebutuhan Pengguna

\begin{tabular}{|l|l|c|c|}
\hline No & Analisis Kebutuhan & Ada & $\begin{array}{l}\text { Tidak } \\
\text { Ada }\end{array}$ \\
\hline 1 & $\begin{array}{l}\text { Menampilkan Menu } \\
\text { Home }\end{array}$ & $\sqrt{ }$ & \\
\hline 2 & $\begin{array}{l}\text { Menampilkan menu } \\
\text { akun pengguna }\end{array}$ & $\sqrt{ }$ & \\
\hline 3 & $\begin{array}{l}\text { Menampilkan menu } \\
\text { kependudukan }\end{array}$ & $\sqrt{ }$ & \\
\hline 4 & $\begin{array}{l}\text { Menampilkan menu } \\
\text { laporan }\end{array}$ & $\sqrt{ }$ & \\
\hline 5 & $\begin{array}{l}\text { Menampilkan data } \\
\text { penduduk masuk }\end{array}$ & $\sqrt{ }$ & \\
\hline 6 & $\begin{array}{l}\text { Menampilkan data } \\
\text { penduduk keluar }\end{array}$ & $\sqrt{ }$ & \\
\hline 7 & $\begin{array}{l}\text { Menampilkan daftar } \\
\text { pengguna }\end{array}$ & $\sqrt{ }$ & \\
\hline 8 & $\begin{array}{l}\text { Menampilkan daftar } \\
\text { semua penduduk RW } \\
\text { VIII }\end{array}$ & $\sqrt{ }$ & \\
\hline 9 & $\begin{array}{l}\text { Menampilkan daftar } \\
\text { penduduk per-RT }\end{array}$ & $\sqrt{ }$ & \\
\hline
\end{tabular}

Berikut ini adalah daftar kegiatan selama PPM Pelatihan Sistem Informasi Administrasi dan
Pencatatan Kependudukan Kampung Gebang Sidoarjo (dapat dilihat di Tabel 7).

Tabel 7 Daftar Sosialisasi Kegiatan

\begin{tabular}{|l|l|l|}
\hline No & Tanggal & Kegiatan \\
\hline 1 & 6 Sept 2021 & $\begin{array}{l}\text { Pelatihan administrasi } \\
\text { dan pencatatan } \\
\text { kependudukan }\end{array}$ \\
\hline 2 & 7 Sept 2021 & $\begin{array}{l}\text { Pelatihan dan pembuatan } \\
\text { akun pengguna untuk } \\
\text { akses Sistem Data } \\
\text { Kependudukan (SIDAK) }\end{array}$ \\
\hline 3 & 8 Sept 2021 & $\begin{array}{l}\text { Pelatihan dan penerapan } \\
\text { input data penduduk } \\
\text { berdasarkan Kartu } \\
\text { Keluarga (KK) dan Kartu } \\
\text { Tanda Pengenal (KTP) } \\
\text { Pada aplikasi Sistem } \\
\text { Data Kependudukan } \\
\text { (SIDAK) }\end{array}$ \\
\hline 4 & 9 Sept 2021 & $\begin{array}{l}\text { Pelatihan pencatatan } \\
\text { penduduk untuk hal-hal } \\
\text { yang bersifat khusus. } \\
\text { Pencatatan Data Masuk } \\
\text { dan Keluar. }\end{array}$ \\
\hline 5 & 10 Sept 2021 & $\begin{array}{l}\text { Penggunaan laporan dan } \\
\text { observasi hasil dari } \\
\text { SIDAK }\end{array}$ \\
\hline & & \\
\hline
\end{tabular}

Pada pelaksaanan kegiatan ini dilakukan selama 5 hari baik secara fisik maupun virtual dalam pelatihan administrasi dan pecatatan kependudukan Kampung Gebang Sidoarjo kepada Perangkat Kampung yang ditunjuk oleh Ketua Rukun Warga (RW) untuk setiap sesinya.

Teknologi Informasi dan Komunikasi 
Berikut ini adalah kegiatan sosialisasi yang dilakukan oleh tim pengabdian kepada masyarakat kepada perangkat Rukun Warga (RW) Kampung Gebang Sidoarjo.

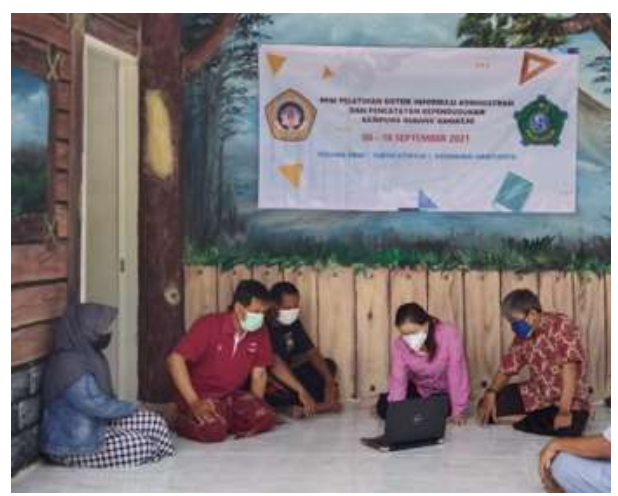

Gambar 6 Sosialisasi Bersama Perangkat Kampung Gebang Sidoarjo.

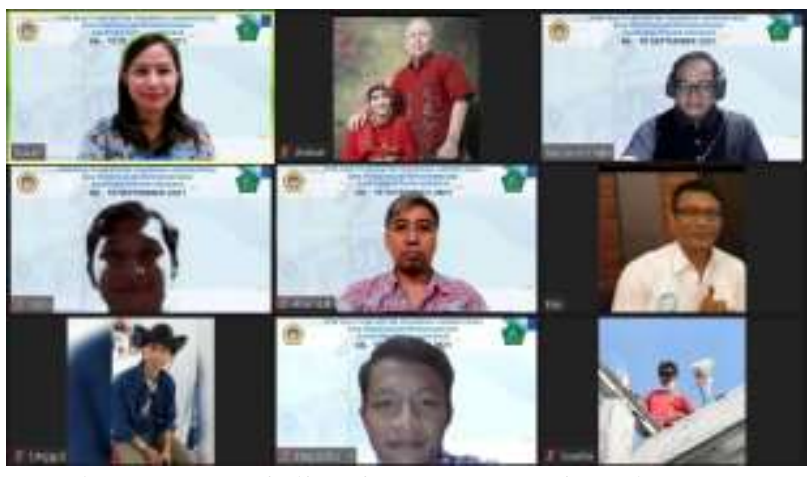

Gambar 7 Sosialisasi Secara Virtual Bersama

Perangkat Kampung Gebang Sidoarjo.

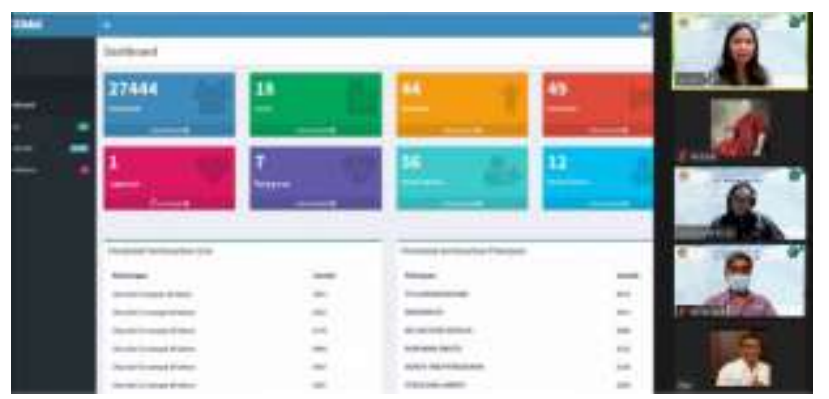

Gambar 8 Sosialisasi Aplikasi Sistem Data Kependudukan (SIDAK).

\section{Kesimpulan}

1. Dari pelatihan Sistem Informasi Administrasi dan Pencatatan Kependudukan kampung Gebang Sidoarjo dapat memberikan informasi dan pengetahuan tentang pencatatan atau penghitungan jumlah data penduduk kepada RT/RW Gebang Sidoarjo.

2. Dapat memberdayakan masyarakat dalam membangun kemampuan daerah sekaligus meningkatkan sumber daya manusia melalui sistem data kependudukan di RW Gebang Sidoarjo yang berbasis Iptek yang berkelanjutan.

3. Dapat menerapkan aplikasi dalam pengakuratan data penduduk.

4. Hasil kegiatan PPM bagi masyarakat Gebang yang telah dilakukan oleh tim pengabdi Universitas Wijaya Putra diperoleh hasil bahwa Perangkat Kampung Gebang dapat lebih mudah mengakses data kependudukan yang dibutuhkan. Dan dapat memaksimalkan penguasaan terhadap Sistem Informasi Administrasi dan Pencatatan Kampung Gebang Sidoarjo.

\section{REFERENSI}

Ali Ibrahim, A. R. (April 2016). RANCANG BANGUN APLIKASI PENCATATAN DATA KEPENDUDUKAN . Jurnal Sistem Informasi (JSI), VOL. 8, NO. 1.

Chindra, S. d. ( 2017). Analisa dan Perancangan Sistem Informasi Administrasi . Jurnal Manajemen Sistem Informasi Vol 2 No 3.

Erlinda. (Juni 2018 ). PENGOLAHAN DATA SENSUS

PENDUDUK 
MENGGUNAKAN. JURNAL TEKNOLOGI DAN OPEN SOURCE VOL. 1 No. 1.

Fikry, M. (2016). RANCANGAN BASIS DATA KEPENDUDUKAN BERDASARKAN ASPEK-ASPEK KUALITAS SCHEMA
DATABASE. e-Journal Techsi Teknik Informatika Vol 8, No 2 .

Rusydi, I. (Juli 2017). PERANAN PERKEMBANGAN TEKNOLOGI INFORMASI. Jurnal Warta Edisi : 53. 